\section{International Scientific Journal Theoretical \& Applied Science}

p-ISSN: 2308-4944 (print) e-ISSN: 2409-0085 (online)

Year: 2015 Issue: 05 Volume: 25

Published: $30.05 .2015 \quad$ http://T-Science.org
Galina Vadimovna Belekhova Junior scientific associate Way and Standard of Living Researching Department Institute of Socio-Economic Development of Territories of Russian Academy of Science (ISEDT RAS), Russia belek-galina@yandex.ru

Alexander Igorevich Rossoshansky Junior scientific associate Way and Standard of Living Researching Department Institute of Socio-Economic Development of Territories of Russian Academy of Science (ISEDT RAS), Russia

alexanderrossy@mail.ru

SECTION 31. Economic research, finance, innovation, risk management.

\title{
WELFARE OF THE POPULATION OF THE REGION: BASIC TRENDS AND PRESENT STATE
}

Abstract: The article presents the results of the population welfare research in the Vologda region in 20002013. The conclusion of the article is based on an analysis of official statistical information. It is also supplemented by the results of social research of the population of the Vologda Region. The revealed trend shows the increase of the population welfare while the maintaining problem of worsening financial position of low-income groups hides behind the averaged data.

Key words: welfare of population, incomes and expenses, inequality.

Language: Russian

Citation: Belekhova GV, Rossoshansky AI (2015) WELFARE OF THE POPULATION OF THE REGION: BASIC TRENDS AND PRESENT STATE. ISJ Theoretical \& Applied Science 05 (25): 73-78.

Soi: http://s-o-i.org/1.1/TAS*05(25)15 Doi: crossef http://dx.doi.org/10.15863/TAS.2015.05.25.15

\section{БЛАГОСОСТОЯНИЕ НАСЕЛЕНИЯ РЕГИОНА: КЛЮЧЕВЫЕ ТЕНДЕНЦИИ И СОВРЕМЕННОЕ СОСТОЯНИЕ}

Аннотация: В статье представлены результаты исследования благосостояния населения Вологодской области за 2000-2013 г2. Выводы статьи базируются на анализе официальной статистической информации, а также дополнены результатами социологических опросов населения региона. Выявлена тенденция к росту благосостояния населения региона при сохранении проблемы худшего материального положения малообеспеченных групп населения, скрытого за средними показателями.

Ключевые слова: благосостояние населения, доходы и расходы, неравенство.

Основополагающей целью государственного управления является создание условий, обеспечивающих достижение высокого уровня жизни граждан, достойное существование и свободное развитие для каждого человека $[1 ; 2]$. С другой стороны, нельзя забывать о стоящих перед страной задачах модернизации всех отраслей хозяйственной и общественной жизни. Для обеспечения передовых темпов развития общества и экономики требуется не только достижение определенного уровня инновационного, технического и социокультурного прогресса, но и наличие условий, мобилизующих социум для модернизации [3, с. 69]. К числу последних относится стабильный рост благосостояния жителей государства.

Следовательно, одна из ключевых задач деятельности органов государственной власти состоит в обеспечении количественного роста и качественного улучшения благосостояния населения страны.

Благосостояние населения формируется в результате эффективного производства, распределения и потребления совокупности материальных и нематериальных благ $[4$, с. $42 ; 5$, c. 14]. Благосостояние в широком смысле слова включает в себя как базисные элементы человеческой жизнедеятельности (уровень доходов, состояние здоровья, наличие и характер работы, потребление товаров и услуг и т.д.), так и элементы, имеющие субъективную, психологическую природу (отношения в семье, социальные настроения, участие в общественной жизни и др.).

Bce подходы к оценке и измерению благосостояния условно можно разделить на два: субъективный и объективный. В первом случае человек сам оценивает свое материальное благосостояние и другие составляющие его 
Impact Factor ISRA (India) $\quad=\mathbf{1 . 3 4 4}$

Impact Factor ISI (Dubai, UAE) $=\mathbf{0 . 8 2 9}$

based on International Citation Report (ICR)

Impact Factor GIF (Australia) $\quad \mathbf{0} \mathbf{0 . 3 5 6}$
Impact Factor JIF $\quad=\mathbf{1 . 5 0 0}$

Impact Factor SIS (USA) $\quad=\mathbf{0 . 9 1 2}$

Impact Factor РИНЦ (Russia) $=\mathbf{0 . 1 7 9}$

Impact Factor ESJI $(\mathrm{KZ}) \quad=\mathbf{1 . 0 4 2}$ жизни. Такое субъективное измерение возможно осуществить только с помощью социологических методов (опросы, интервьюирования, фокусгруппы, наблюдения). Во втором случае на базе официальной статистической и ведомственной информации с помощью методов экономикоматематического анализа оцениваются объективные компоненты благосостояния (уровень доходов, имущественная обеспеченность, благоустроенность жилья, условия труда, возможности доступа к общественным благам и т.д.).

Материальные

составляющие благосостояния населения, и прежде всего денежные доходы, могут быть оценены с относительно высокой степенью надежности и достоверности. Поэтому в экономической науке и практике широко распространен подход, в котором благосостояние населения анализируется в разрезе показателей, характеризующих объем, структуру, основные направления использования и распределения денежных доходов населения. Представим основные результаты подобного анализа, который был проведен по материалам Вологодской области.

Многочисленные

исследования подтверждают, что в среднем по стране уровень благосостояния населения растет [6, 7, 8, 9], однако между отдельными регионами наблюдается значительные разрывы по степени материальной обеспеченности населения.
Согласно рейтингу регионов по уровню жизни семей, подготовленному экспертами агентства «РИА Рейтинг», в 2013 году в среднестатистической российской семье, состоящей из двух работающих взрослых и двух детей, ежемесячно после удовлетворения базовых потребностей остается 30134 руб. (27 тыс. руб. в 2012 году, 20770 руб. в 2011 г.). При этом разрыв между регионами, занимающими первое и последнее место в рейтинге, составляет более 13 раз (Ямало-Ненецкий АО - 95545 руб., Республика Дагестан - 7202 руб.). Вологодская область в данном рейтинге стабильно занимает место в четвертом десятке (37 место в 2012 г. 19125 руб., 38 место в 2013 г. - 19813 руб.) [10].

Еще одной общероссийской тенденцией, складывающейся на протяжении уже более десяти лет, является повышение среднедушевых денежных доходов при неизменном росте их неравномерного распределения среди населения. Согласно данным официальной статистики за период 2000-2013 гг. среднедушевые денежные доходы жителей Вологодской области в сопоставимой оценке увеличились в 2,8 раза (в среднем по России чуть больше - в 3 раза). Аналогичный рост фиксируется по заработной плате и пенсиям, при этом в связи со значительным повышением пенсионного обеспечения размер назначенных пенсий увеличивался быстрее по сравнению с заработной платой - 3,2 против 2,7 раз (табл. 1).

Таблица 1

Динамика доходов населения Российской Федерации и Вологодской области в 2000-2013 гг.*, руб.

\begin{tabular}{|c|c|c|c|c|c|c|c|c|c|}
\hline \multirow{2}{*}{ Показатели } & \multicolumn{8}{|c|}{ Год } & \multirow{2}{*}{$\begin{array}{r}\text { Изм-е } \\
2013 \text { г. к } \\
2000 \text { г., pa } \\
\end{array}$} \\
\hline & 2000 & 2005 & 2008 & 2009 & 2010 & 2011 & 2012 & 2013 & \\
\hline \multicolumn{10}{|c|}{ Российская Федерациия } \\
\hline \begin{tabular}{|l} 
Среднедушевые \\
денежные доходы \\
населения
\end{tabular} & 8513 & 15938 & 21194 & 22142 & 22836 & 23591 & 24730 & 25928 & 3,0 \\
\hline $\begin{array}{l}\text { Среднемесячная } \\
\text { начисленная } \\
\text { заработная плата } \\
\end{array}$ & 8296 & 16857 & 24562 & 24426 & 25528 & 26898 & 28360 & 29792 & 3,6 \\
\hline \begin{tabular}{|l} 
Средний размер \\
начисленных \\
месячных пенсий
\end{tabular} & 2590 & 4658 & 6482 & 6803 & 9005 & 9313 & 9749 & 10030 & 3,9 \\
\hline \multicolumn{10}{|c|}{ Вологодская область } \\
\hline \begin{tabular}{|l} 
Среднедушевые \\
денежные доходы \\
населения
\end{tabular} & 7350 & 12550 & 17197 & 16054 & 16955 & 17771 & 19562 & 20513 & 2,8 \\
\hline $\begin{array}{l}\text { Среднемесячная } \\
\text { начисленная } \\
\text { заработная плата } \\
\end{array}$ & 9308 & 174612 & 22092 & 21730 & 22266 & 23013 & 24280 & 25127 & 2,7 \\
\hline Средний & 3179 & 5167 & 6537 & 8261 & 9381 & 9668 & 10092 & 10309 & 3,2 \\
\hline
\end{tabular}

ISPC Industry \& Technology Europe, 


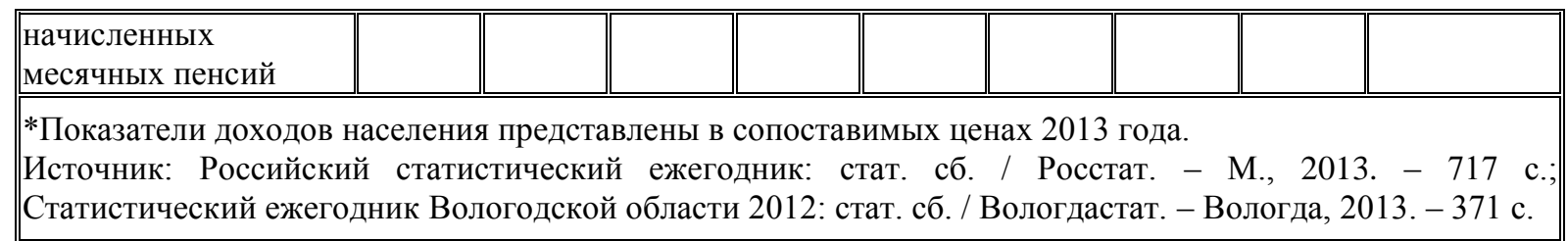

Но одновременно с повышением средних размеров денежных выплат усиливалась и социально-экономическая дифференциация населения, формируемая за счет ускоренного роста доходов высокообеспеченных слоев населения. Коэффициент фондов, определяющийся как соотношение средних доходов $10 \%$ наиболее обеспеченной части населения к средним доходам 10\% наименее обеспеченной части, в 2013 году составил 12 раз, в 2000 г. - 14 раз. Однако показатели дифференциации доходов населения Вологодской области ниже общероссийских (в 2013 г. по области коэффициент фондов составлял 12 раз, а индекс Джини - 0,376, тогда как в России они были равны 16,2 раз и 0,418 соответственно).

Анализ распределения населения по квинтильным доходным группам позволяет говорить о том, что условия, которые создавались в течение 2000-х годов, положительно повлияли только на наиболее обеспеченную часть населения. Материальное положение низкодоходных групп, как в России, так и в Вологодской области, существенно не менялось, а уровень доходов не превышал даже величины прожиточного минимума (в Вологодской области денежные доходы первой квинтильной группы составляли в 2000 г. $77 \%$, а в 2013 г. $85 \%$ от величины прожиточного минимума). В тоже время предельно критическое значение по показателю соотношения душевых доходов и минимального уровня потребления (в нашем случае, с прожиточным минимумом) для развитых стран мира составляет 3,5 раза $[11$, с. 26], что соотносится лишь с уровнем пятой доходной группы в стратификационной структуре населения Вологодской области (табл. 2). Фактически потребление порядка $80 \%$ жителей региона ниже предельно критических значений [9, с. 37-38].

Таблица 2

Отношение среднедушевых денежных доходов населения Вологодской области к величине прожиточного минимума по 20\% группам населения, 2000-2013 гг.

\begin{tabular}{|c|c|c|c|c|c|c|c|c|c|c|}
\hline \multirow{2}{*}{$\begin{array}{c}\text { Квинтильные } \\
\text { группы }\end{array}$} & \multicolumn{9}{|c|}{ Год } & \multirow{2}{*}{$\begin{array}{c}\text { Изменение } \\
2013 \text { г. к } \\
2000 \text { г., ра3 }\end{array}$} \\
\hline & 2000 & 2005 & 2007 & 2008 & 2009 & 2010 & 2011 & 2012 & 2013 & \\
\hline Первая (нижняя) & 0,77 & 0,74 & 0,80 & 0,78 & 0,73 & 0,77 & 0,75 & 0,85 & 0,85 & 1,10 \\
\hline Вторая & 1,27 & 1,28 & 1,45 & 1,41 & 1,30 & 1,35 & 1,34 & 1,50 & 1,52 & 1,20 \\
\hline Третья & 1,71 & 1,83 & 2,11 & 2,03 & 1,86 & 1,94 & 1,91 & 2,16 & 2,18 & 1,27 \\
\hline Четвертая & 2,32 & 2,61 & 3,10 & 2,96 & 2,66 & 2,79 & 2,75 & 3,13 & 3,16 & 1,36 \\
\hline Пятая (верхняя) & 3,99 & 4,90 & 6,08 & 5,76 & 5,07 & 5,34 & 5,19 & 6,02 & 6,08 & 1,53 \\
\hline
\end{tabular}

В Вологодской области, как и в других регионах страны, основным источником доходов населения является заработная плата, хотя её роль постепенно снижается (52\% в 2000 г., $45 \%$ в 2013 г.). Продолжает сокращаться и вклад тех источников, которые характеризуют экономическую активность населения - дохода от предпринимательской деятельности (с 10\% в 2000 г. до 8,4\% в 2013 г.) и поступлений от собственности. Одновременно в структуре доходов населения региона, особенно с 2008 г., возрастает доля социальных трансфертов (с 17\% в 1998 г. до $25 \%$ в 2013 г.). Однако, как свидетельствует коэффициент замещения, размер пенсионных выплат по-прежнему недостаточен для того, что обеспечить адекватную замену заработной платы. В Вологодской области значение данного показателя несколько больше, чем по стране в целом - $42 \%$ за 2010-2013 гг. (в России 
коэффициент замещения долгое время не превышал 28-31\%; в $2012-2013 \quad$ г. стабилизировался на уровне $34 \%$ ), но до уровня многих развитых и развивающихся стран мира мы всё равно не дотягиваем (по данным Организации экономического сотрудничества и развития коэффициент замещения в 2013 г. составил в Нидерландах 91,4\%, Дании - 83,7\%, Турции - 66,8\%, Франции - 59,1\%, Эстонии $55,3 \%$ [12]) [13, с. 265-266].

Наряду с доходами важнейшей характеристикой благосостояния выступают потребительские расходы населения. В связи с ростом реальных денежных доходов населения Вологодской области имело место значительное увеличение потребления (более чем в 3 раза в реальном выражении - с 4247 руб. в 2000 г. до 13153 руб. в 2013 г.). Оно сопровождалось положительной тенденцией перераспределения потребительских расходов от покупки продуктов питания (его доля снизилась с $49 \%$ в 2000 г. до $37 \% \quad$ в $2013 \quad$ г.) $\quad$ в пользу приобретения непродовольственных товаров и оплаты услуг (их суммарная доля выросла с 47 до $61 \%$ соответственно) [9, с. 31]. Однако структура потребительских расходов населения Вологодской области всё еще далека от мировых стандартов (например, в странах Западной Европы на питание тратится около 20\%).

За 2000-2013 гг. структура потребительских расходов $10 \%$ наиболее и $10 \%$ наименее обеспеченных жителей Вологодской области заметно выровнялась. К положительным изменениям в обеих группах следует отнести снижение удельного веса расходов на питание (с 69 до 45\% в группе бедных и с 36 до $33 \%$ в группе богатых) и рост затрат на оплату услуг (с 11 до 30\% и с 11 до 24\% соответственно).

Однако структура потребления с точки зрения товарных позиций существенно разнится у крайних доходных групп. По состоянию на 2012 год наиболее обеспеченные жители Вологодской области потребляли в 3,4 раза больше фруктов и ягод, в 2,8 раза - овощей, в 2,2 раза - рыбных продуктов, в 2,1 раза - мясных продуктов, в 2,7 раза - молочных продуктов. Наименьшее расхождения в объемах потребления наблюдается по хлебным продуктам $(0,9$ раз) и картофелю (0,9 раз).

Кроме того, учитывая опережающий рост цен на продукты питания и платные услуги, являющихся базой потребительских расходов наименее обеспеченных слоев населения, можно говорить об относительном снижении покупательной способности их доходов по сравнению с доходами наиболее обеспеченных.

Выявленные выше тенденции изменения уровня жизни населения Вологодской области находят свое отражение и в субъективных характеристиках населением региона уровня своего благосостояния. Его изучение осуществляется Институтом социальноэкономического развития территорий РАН (ИСЭРТ РАН) в рамках социологических опросов населения региона. Согласно результатам наблюдений, в структуре жителей области по уровню покупательной способности доходов преобладающей на протяжении последних 10 лет является группа «малообеспеченного» населения (56\%), свободно распоряжающегося денежными средствами в рамках базовых потребностей, но испытывающая затруднения в приобретении товаров длительного пользования и оплате других дорогих продуктов и услуг. Самыми малочисленными являются слои «обеспеченных» и «богатых»: $13 \%$ способны без труда покупать большинство товаров длительного пользования, $3 \%$ не отказывают себе ни в чём.

Несмотря на повышение удельного веса положительных оценок качества питания в среднем по региону, сохраняется закономерность: чем выше уровень доходов, тем разнообразнее и качественнее питание. Среди 20\% наименее обеспеченной части населения преобладают удовлетворительные оценки качества питания (56\% в 2014 году) и велика доля тех, кто оценивает его как однообразное $(26 \%)$, в то время как представители высокодоходного квинтиля характеризуют питание как хорошее (64\%) и очень хорошее $(8 \%)$. Большая часть жителей области, входящих в группу « $20 \%$ наименее обеспеченных» приобретает только самые необходимые продукты (64\%) и услуги (52\%), в то время как в полярной группе половина (50\%) может позволить себе приобретение любых продуктов и услуг, кроме самых дорогостоящих. Bce это свидетельствует об ограниченном участии низкодоходных семей в иных секторах потребительского рынка, кроме рынка продуктов питания и других товаров первоочередного спроса [14, с. 33].

Согласно данным социологических опросов, проводимых ИСЭРТ РАН на территории Вологодской области, наиболее острые и значимые проблемы для населения связаны с благосостоянием и уровнем жизни. Всегда входят в пятерку ключевых такие проблемы, как «низкий уровень жизни и бедность» (в 1998 году доля респондентов, отметивших данную проблему, составила $43 \%$ от числа опрошенных, в 2014 г. - 38\%), «расслоение населения на «бедных» и «богатых» $(23 \%$ и $37 \%$ соответственно), «проблема жилищного обеспечения и низкая доступность жилья» (10\% и $29 \%$ ). Становясь повседневной частью сознания жителей региона, данные аспекты вызывают чувство социального недовольства, которое влияет на сохранение социальной напряженности 
в обществе и сказывается на оценках политической и экономической обстановки, уровне одобрения деятельности федеральным и региональным органам власти.

Следовательно, государственные структуры (федеральные, региональные) должны обязательно сопровождать свою деятельность мероприятиями по созданию условий для повышения благосостояния и уровня жизни. Необходимы не только апостериорные меры социальной поддержки, но и превентивные действия. Примером работы органов власти в этом направлении является повсеместно декларируемая модернизация сфер общественной жизни, направленная прежде всего на развитие науки, информационных технологий и постиндустриальные отрасли (в которых даже в развитых странах занята незначительная часть населения [15, с. 16]). Однако, учитывая, что по результатам социологических исследований ИСЭРТ РАН наиболее уязвимые группы малообеспеченного населения, для которых характерны депрессивные настроения и низкий уровень одобрения и поддержки власти, составляют рабочие промышленных предприятий, работники сельского хозяйства и специалисты низшего звена в коммерческих предприятиях, мероприятия по повышению уровня жизни населения должны быть связаны в первую очередь с восстановлением и модернизацией индустриального сектора. Представленная выше оценка аспектов благосостояния, в свою очередь, может стать одним из аналитических инструментов, который позволит выявить проблемные аспекты жизненных условий населения и определить ориентиры социально-экономической политики региональных властей на перспективу.

\section{References:}

1. (2015) Konstitutsiya Rossiyskoy Federatsii [Electronic resource]. - Available: http://www.consultant.ru/popular/cons/

(Accessed: 19.03.2015)

2. (2015) Ukaz Prezidenta Rossiyskoy Federatsii ot 12 maya 2009 g. № 537 «O Strategii natsionalnoy bezopasnosti Rossiyskoy Federatsii do 2020 goda» [Electronic resource] / Rossiyskaya gazeta. - Available: http://www.rg.ru/2009/05/19/strategia-dok.html (Accessed: 19.03.2015)

3. Shabunova AA (2014) Preodolenie sotsialnogo neravenstva kak impuls $\mathrm{k}$ sotsiokulturnoy modernizatsii [Text] / A.A. Shabunova, M.A. Lastochkina // Ekonomicheskie i sotsialnyie peremenyi: faktyi, tendentsii, prognoz. - 2014. - № 3 (33). - pp. 69-83.

4. Karpunina EK (2010) Usilenie sotsialnoy orientatsii gosudarstvennoy politiki Rossii kak neobhodimoe uslovie povyisheniya blagosostoyaniya naseleniya [Text] / E.K. Karpunina, O.V. Yudin // Sotsialnoekonomicheskie yavleniya i protsessyi. - 2010 . - № 5. - pp. 41-46.

5. Dorosh AA (2010) Obschestvennoe blagosostoyanie kak faktor formirovaniya novoy ekonomiki [Text]: avtoreferat na soiskanie uchenoy stepeni kandidata ekonomicheskih nauk po spetsialnosti 08.00.01. - Moscow, 2010. - 28 p.
6. Bobkov VN (2012) Neravenstvo kachestva i urovnya zhizni naseleniya regionov [Text] / V.N. Bobkov, A.A. Gulyugina // Ekonomika regiona. - 2012. - № 2. - pp. 170-178.

7. Ovcharova LN (2013) Dohodyi i rashodyi rossiyskih domashnih hozyaystv: chto izmenilos $\mathrm{v}$ massovom standarte potrebleniya [Text] / L.N. Ovcharova, D.O. Popova // Mir Rossii. - 2013. - № 3 - pp. 3-34.

8. (2011) Uroven i obraz zhizni naseleniya Rossii v 1989-2009 godah [Text]: dokl. k XII Mezhdunar. nauch. konf. po problemam razvitiya ekonomiki i obschestva, Moskva, 5-7 apr. 2011 g. / ruk. avt. koll. E. G. Yasin; Nats. issled. un-t «Vyisshaya shkola ekonomiki». Moscow: Izd. dom Vyisshey shkolyi ekonomiki, 2011. - 86 p.

9. Shabunova AA (2014) Blagosostoyanie naseleniya: tendentsii i perspektivyi [Text] : monografiya / A.A. Shabunova, A.I. Rossoshanskiy, G.V. Belekhova. - Vologda : ISERT RAN, 2014. - 124 p.

10. (2014) Reyting regionov po urovnyu zhizni semey - 2014 [Electronic resource] / RIA Reyting. Available: http://riarating.ru/infografika/20140707/610622 475.html (Accessed: 12.04.2015)

11. Glazev SY (2012) Otsenka predelno kriticheskih znacheniy pokazateley sostoyaniya rossiyskogo obschestva $\mathrm{i}$ ih ispolzovanie $\mathrm{v}$ upravlenii sotsialno-ekonomicheskim razvitiem 
[Text] / S.Yu. Glazev, V.V. Lokosov // Ekonomicheskie i sotsialnyie peremenyi: faktyi, tendentsii, prognoz. - 2012. - № 4. - pp. 22-41.

12. Pensions at a Glance 2013 [Electronic resource]: Retirement-Income Systems in OECD and G20 Countries. - Available: http://www.oecd.org/pensions/pensionsataglanc e.htm (Accessed: 11.05.2015)

13. Rossoshanskiy AI (2014) Blagosostoyanie naseleniya kak pokazatel modernizatsionnogo potentsiala territorii [Text] / A.I. Rossoshanskiy, G.V. Belekhova // Ekonomicheskie i sotsialnyie peremenyi: faktyi, tendentsii, prognoz. - 2014. - № 5 (35). - pp. 260-275.

14. Rossinskaya GM (2009) Potrebitelskoe povedenie domohozyaystva $\mathrm{v}$ usloviyah transformatsii rossiyskogo obschestva [Text] / G.M. Rossinskaya // Vestnik UGATU. - 2009. - № 3 (32). - pp. 22-36.

15. Belyaeva LA (2011) Dinamika otnosheniya rossiyan k sotsialno-ekonomicheskim i politicheskim izmeneniyam [Text] / L.A. Belyaeva // Sotsiologicheskie issledovaniya. 2011. - № 10. - pp. 11-25. 